\title{
EFFECT OF ACIDIC DRINKS ON COLOR STABILITY OF DIFFERENT DIRECT BULK-FILL RESIN COMPOSITE RESTORATIONS
}

\author{
Nadia M. Zaghloul ${ }^{*}$ and Ashraf I. Ali**
}

\begin{abstract}
Introduction: Although resin composite restoration is now considered one of the most commonly used esthetic restoratives, color stability of restorations is the major demand for a successful and durable restoration. However acidic drinks have a discoloring effect on it

Aim of the study: This study aimed to evaluate the effect of acidic drinks on color stability of different direct Bulk-Fill Resin composite restorations.

Materials and methods: A total of 90 standardized disc shaped specimens were constructed, 30 from each restorative material $(n=30)$, Filtek bulk-fill Posterior Restorative, TetricEvoCeram bulk-fill, and SonicFill resin composites using a customized split Teflon mold, with an internal space of $10 \mathrm{~mm}$ diameter and $2 \mathrm{~mm}$ thickness. Each specimen was photo-cured for 20 seconds, using a LED curing unite. Specimens of each restorative material were divided into three subgroups according to storage media used to store in $(n=10)$; orange juice, Coca cola and artificial saliva. Color measurements were recorded for all specimens using Spectrophotometer before and after storage for 48 hour in the media. Finally, the values of $\Delta \mathrm{E}$ were submitted to statistical analysis.
\end{abstract}

Results: Coca Cola caused the highest degree of discoloration of the resin composites, to be followed by Orange juice with the least color changes were noticed with storage in the Artificial saliva ( $\mathrm{p}<0.0001$ ). Regarding to the bulk-fill resin composites, Filtek Posterior revealed the lowest levels of color change while the highest levels of discoloration were noticed with SonicFill bulk-fill resin composite, regardless the type of storage media ( $p>0.05)$.

Conclusion: Bulk-fill resin composites, investigated in this study, showed less color stability than incremental resin composites. Acidic drinks have deteriorating effects on color of resin composite restorations.

KEYWORDS: Color stability, Bulk-Fill resin composite, Acidic drinks.

* Assistant Professor, Department of Operative Dentistry, Faculty of Dentistry, Mansoura University, Mansoura, Egypt.

** Lecturer, Department of Operative Dentistry, Faculty of Dentistry, Mansoura University, Mansoura, Egypt. 


\section{INTRODUCTION}

There is a growing attention to the beauty since the earliest civilizations. Resin composites have become a part of this quest to enhance teeth and mouth esthetics. Although resin composite restoration is now considered one of the most commonly used esthetic restoratives, several drawbacks still facing the clinicians. One of the inevitable drawbacks of dental resin composites is its polymerization shrinkage, which may be as high as $3 \%$ by volume. ${ }^{1,2}$ This volumetric shrinkage leads to stresses development. Polymerization stresses at the restoration/tooth interface result in either adhesive de-bonding with gap formation ${ }^{3}$ or cusp deformation which might cause microcracks and/or cusp fracture. ${ }^{4}$ Many clinical methods have been proposed to reduce the polymerization shrinkage stresses, such as the control of the curing light intensity, ${ }^{5}$ flowable resin liner application, ${ }^{6}$ indirect resin restoration, ${ }^{7}$ and incremental layering techniques. ${ }^{8}$ However, no method has been shown to be totally effective in abating the effects of polymerization shrinkage.

Despite the controversy over the advantages of incremental build-up of composites, ${ }^{9-13}$ this technique has been broadly recommended for direct resin-composite restorations, because it is expected to decrease the configuration factor, allowing a certain amount of flow to partially dissipate the shrinkage stress. ${ }^{13}$ However, despite of these advantages, incremental technique has a number of disadvantages such as; entrapment of voids between the increments, bond failure between the increments and the time required to complete the procedure placement and polymerization of each separate increment. ${ }^{3,14}$ In order to overcome many of the downsides associated with the incremental placement approach of resin composites, new restorative materials have emerged and are marketed as bulk-fill composites. However, dentists who have become accustomed to the incremental philosophy of placing light-cured composites quite rightly question what specifically has changed to make these bulk-fill composites a viable alternative ${ }^{15}$.

Bulk-fill resin-based composites are toothcolored restorative materials with increased polymerization depth, decreased polymerization shrinkage stresses and suspected decreased cuspal deflection and gap formation rate. Unlike to the conventional resin-based composites they can be applied into the prepared cavities in layers up to 4 or $5 \mathrm{~mm}$ thick ${ }^{16}$. According to some researchers these bulk-fill composites offer a number of advantages for restoring preparations such as simplifying the restorative process and saving time.Furthermore, bulk-fill composites eliminate many of the drawbacks that are associated with incremental layering techniques, such as the risk of contamination and voids forming between the increments ${ }^{17-19}$.

The general practitioner, however, is rather confused with the variety of different bulk-fill materials on the market and the way they are promoted. The most common method to promote and market these products is by presenting data gained from laboratory tests. Continuing research into practical advances and successful clinical evaluations of composite restoratives are critical to oral care, esthetics, and functional restoration. ${ }^{20}$

The evolved bulk-fill resin-based composites are mainly classified into flowable type, that requires an additional layer of conventional resin, and highviscosity types. ${ }^{21}$ These materials contain monomer structures and filler compositions almost identical to conventional resin composites. The main difference is the polymerization modulators and plasticizers which are incorporated to modulate polymerization kinetics. ${ }^{22}$ Added to this; the percentage of filler content has been reduced in bulk-fill resin composites to facilitate deep light transmission up to $4-5 \mathrm{~mm}$. Mostly, the conducted studies of bulkfill resin based composites have been focused on the polymerization-related properties, depth of cure, degree of monomer conversion, sorption and solubility, polymerization shrinkage stress, 
cytotoxicity, as well as micro-hardness and wear resistance of the high viscosity types. ${ }^{23-26}$

In the era of esthetic restorations, color stability of restorations is the major demand for a successful and durable restoration. A successful restoration should not only demonstrate high physical and mechanical properties, but also should be appealing esthetically. Despite the advances in resin monomers and filler particle technology, color stability of direct resin composite restorations has been still a great problem. Color changes could be caused by either intrinsic factors or extrinsic factors. The intrinsic factors might be related to composition of the resin matrix, filler composition, degree of monomer conversion, in addition to the type of photo-initiator, which is responsible for yellow-shifts taking place over time..$^{27,28}$ External discoloration can be caused by oral habits such as tobacco and certain dietary patterns, along with bad oral hygiene and the adsorption or absorption of water soluble stains throughout the resin matrix. ${ }^{29-31}$

Acidic drinks are the most common beverages consumed many times daily throughout the world, and a large amount of evidence considering them as a part of oral tissues as teeth, saliva and restorations. Therefore, it is necessary to investigate the potential risk that the consumption of these beverages poses to new bulk-fill resin composites. Several studies assessed color stability have shown that beverages such as coffee, tea, and cola produce varying levels of discolorations in photo-cured resin composites restoratives..$^{29,32,33}$ Therefore, a study to evaluate the color changes of different direct bulk-fill resin composite maybe of value.

\section{MATERIALS SELECTION}

This in-vitro study included three bulk fill dental resin composites, of A2 shade i.e., Filtek bulk-fill Posterior Restorative, TetricEvoCeram bulk-fill and SonicFillNanohybrid. The materials were selected on the basis of initiator type and resin monomer variation within the major category of bulk-fill resin based composites. The descriptions of the materials investigated are represented in Table 1. Two different types of acidic drinks; orange juice and Coca-cola, and artificial Saliva, as a control, were represented in Table 2.

TABLE (1) The bulk fill dental resin composites used.

\begin{tabular}{|c|c|c|c|}
\hline Restorative system & Manufacturer & Composition & Filler loading \\
\hline \multirow[t]{2}{*}{$\begin{array}{l}\text { Filtek bulk-fill } \\
\text { Posterior Restorative }\end{array}$} & \multirow[t]{2}{*}{$\begin{array}{r}\text { 3M ESPE, St. } \\
\text { Paul, MN, USA }\end{array}$} & $\begin{array}{l}\text { Matrix Aromatic UDMA, UDMA, ERGP-DMA, } \\
\text { Diurethane-DMA and 1,2- dodecane-DMA }\end{array}$ & \multirow[t]{2}{*}{$\begin{array}{l}58.4 \text { vol } \% \\
76.5 \text { weight } \%\end{array}$} \\
\hline & & $\begin{array}{l}\text { Filler Non-agglomerated/non aggregated } 20 \mathrm{~nm} \text { filler, } \\
\text { non agglomerated/non aggregated } 4_{-} 11 \text { zirconia filler, } \\
\text { aggregated zirconia/silica cluster filler and a ytterbium } \\
\text { trifloride filler }\end{array}$ & \\
\hline \multirow[t]{2}{*}{$\begin{array}{l}\text { TetricEvoCeram bulk-fill } \\
\text { (nanohybrid) }\end{array}$} & \multirow{2}{*}{$\begin{array}{l}\text { Ivoclar Vivadent, } \\
\text { Schaan, } \\
\text { Liechtenstein }\end{array}$} & $\begin{array}{l}\text { Matrix } \\
\text { UDMA, Bis-GMA }\end{array}$ & \multirow[t]{2}{*}{$\begin{array}{l}60-61 \text { vol } \% \\
79-81 \text { weight } \%\end{array}$} \\
\hline & & $\begin{array}{l}\text { Filler Barium glass, ytterbium trifluoride, mixed oxide } \\
\text { and pre polymer }\end{array}$ & \\
\hline \multirow[t]{2}{*}{ SonicFill (Nanohybrid) } & \multirow{2}{*}{$\begin{array}{c}\text { Kerr } \\
\text { Corporation }\end{array}$} & Matrix Bis -GMA, TEGDMA, EBpDMA & \multirow[t]{2}{*}{83 weight $\%$} \\
\hline & & Filler Silicon dioxide, barium glass & \\
\hline \multicolumn{4}{|c|}{$\begin{array}{l}\text { Abbreviations: Bis-GMA, Bisphenol glycidyl dimethacrylate; HEMA, hydroxyl ethyl methacrylate; DMA,dimethacrylate; } \\
\text { TEGDMA, Tri-ethylene glycol dimethacrylate; UDMA, Urethane Dimethacrylate; Bis-EMA,Bisphenol Apolyethylene } \\
\text { glycol diether dimethacrylate; GPDM, Glycero phosphate dimethacrylate; EBPDMA, Exthoxylated Bisphenol A } \\
\text { dimethacrylate }\end{array}$} \\
\hline
\end{tabular}


TABLE (2) Storage media

\begin{tabular}{|c|c|c|}
\hline Product & Manufacturer & Ingredient \\
\hline Orange juice & $\begin{array}{l}\text { Freshly squeezed juice in } \\
\text { Faculty of Pharmacy, Mansoura } \\
\text { University, Mansoura city, Egypt }\end{array}$ & $\begin{array}{l}\text { Chemical composition of the cloud: } \mathrm{pH} 3.30 \text { sugars, organic acids } \\
4.5-32 \% \text { pectin, } 34-52 \% \text { protein, } 25 \% \text { lipids, } 5.7 \% \text { nitrogen, } 2 \% \text { hemi- } \\
\text { cellulose, } 2 \% \text { ash, and less than } 2 \% \text { cellulose }\end{array}$ \\
\hline Coca-Cola & Coca - Cola company egypt & $\begin{array}{l}\mathrm{pH} 2.50 \\
\text { Sugar,caramel coloring, caffeine, phosphoric acid, mixture of essential } \\
\text { oils such as orange, lime, and lemon. } \\
\text { Another ingredient is thought to be Lavender }\end{array}$ \\
\hline $\begin{array}{l}\text { Artificial } \\
\text { saliva }\end{array}$ & $\begin{array}{l}\text { Faculty of Pharmacy, Mansoura } \\
\text { University, Mansoura city, Egypt }\end{array}$ & $\begin{array}{l}\text { Preparation of artificial saliva: } \mathrm{pH} 7.00 \\
\text { 1) Sodium azide: } 0.75 \mathrm{~g} \\
\text { 2) Potassium monohydrogen phosphate: } 0.804 \mathrm{~g} \\
\text { 3) Calcium chloride: } 0.166 \mathrm{~g} \\
\text { 4) Magnesium chloride: } 0.059 \mathrm{~g} \\
\text { 5) Sodium chloride: } 1.02 \mathrm{~g} \\
\text { With Distilled water (ph 7) was added to produce one liter of Artificial } \\
\text { Saliva }\end{array}$ \\
\hline
\end{tabular}

\section{Specimens' preparation}

A total of 90 standardized disc shaped specimens were constructed, 30 from each restorative material $(n=30)$. Filtek bulk-fill Posterior Restorative, TetricEvoCeram bulk-fill, andSonicFill resin compositesrespectively. The discs were fabricated using a customized split Teflon mold, with an internal space of $10 \mathrm{~mm}$ diameter and $2 \mathrm{~mm}$ thickness. The split teflon mold was assembled over a glass slide, covered with a transparent polyester strip (Mylar; SS White Company, Philadelphia, PA, USA). The resin composite material was applied in a single increment. After filling the mold, another polyester strip was pressed onto the filled mold surface with a glass slide and a metal disc weighing $2 \mathrm{~kg}$, for 30 seconds, to obtain a flat smooth surface without air entrapment or gross excess. After that, the metal disc and glass slide were removed and each specimen was photo-cured for 20 seconds, using a LED curing unite at wave length 430-480nm and light intensity of $1200 \mathrm{~mW} / \mathrm{cm}^{2}$ (EliparS10, $3 M$ ESPE AG, Seefeld, Germany). The tip of the light curing unite was placed directly perpendicular to the surface of the top strip. After curing the top surface, the bottom surface of each sample was additionally cured for another 20 seconds to obtain a homogeneous polymerization. The intensity of the light curing device was monitored through procedures of photo-curing using a radiometer (DigiRate LM-100, MONITEX, Tiwan ). As the polyester strip produces a high smooth polished surface, no finishing or polishing were needed. All prepared specimens were then stored in distilled water at $37 \pm 1^{\circ} \mathrm{C}$ for $24 \mathrm{~h}$, to ensure optimum polymerization.

\section{Assessment of color change}

Color measurements were recorded for all specimens according to the Commission International de l'Eclairage (CIE) $\mathrm{L}^{*} \mathrm{a} * \mathrm{~b} *$ color scale, using shimazu UV-3101pc (UV-VIS-NIR Scanning Spectrophotometer: 130 Conway Drivel Suites A, B \& C I Bogart, GA 30622). It should be recalled that the spectrophotometer was calibrated after each measurement. 
In order to evaluate the color stability of each material, the quantitative color measurement of each specimen was first carried out after 24 hours of fabrication (control).The specimens were then divided into three subgroups $(n=10)$ relative to the immersion media. Subgroup I stored in artificial saliva subgroup II stored in Coca cola, subgroup III stored in orange juice. The specimens were individually immersed in vials containing $20 \mathrm{~mL} /$ specimen storage solutions. All the specimens were kept in dark at $37^{\circ} \pm 1 \mathrm{C}$ for a period of 48 hour. ${ }^{34}$ After the experimental period, the specimens were kept for 24 hours in distilled water at $37^{\circ} \pm 1^{\circ} \mathrm{C}$ and again subjected to quantitative color measurement.

The color changes of each specimen was measured by the coordinates $\mathrm{L}^{*}, \mathrm{a}^{*}$ and $\mathrm{b}^{*}$ of the CIEL ${ }^{*} \mathrm{a}^{*} \mathrm{~b}^{*}$ system and calculated using the formula $\Delta \mathrm{E}^{*}=\left[\left(\Delta \mathrm{L}^{*}\right)^{2}+\left(\Delta \mathrm{a}^{*}\right)^{2}+\left(\Delta \mathrm{b}^{*}\right)^{2}\right] 1 / 2$, where $\Delta \mathrm{E}^{*}$ represents the color difference. $\Delta \mathrm{L}^{*}$ represents a measure of the luminosity (varying from 0 to 100 , and means absolute white to absolute black), $\Delta \mathrm{a}^{*}$, $\Delta \mathrm{b}^{*}$ represent changes in chromaticity coordinates with $+a^{*}$ indicates the red direction, $-\mathrm{a}^{*}$ indicates the green direction, $+b^{*}$ indicates the yellow direction and $-b^{*}$ indicates the blue direction.Finally, the values of $\Delta \mathrm{E}$ were submitted to statistical analysis .

\section{RESULTS}

Mean values and standard deviations of color changes $(\Delta \mathrm{E})$ for the three bulk-fill resin composites tested are displayed in Tables 3. Two-way ANOVA indicated significant differences for both resin composite and immersion media factors ( $\mathrm{p}<$ 0.0001). Regarding to the bulk-fill resin composites, Filtek Posterior revealed the lowest levels of color change while the highest levels of discoloration were noticed with SonicFill bulk-fill resin composite, regardless the type of storage media. Tukey's test showed that there are significant differences ( $p<0.0001)$ between the three restorative materials when stored in either Coca Cola or Orange juice. Storage in artificial saliva did not significantly $(\mathrm{p}>$ 0.05 ) affect the color stability of the three restorative materials.

Regardless the restorative materials, Coca Cola caused the highest degree of discoloration of the resin composite, to be followed by Orange juice with the least color changes were noticed with storage in the Artificial saliva. There are significant differences $(p<0.0001)$ in the color stability of the restorative materials when stored in the three different media i.e. Coca Cola, Orange juice and artificial saliva.

TABLE (3) Means and SD of $\Delta \mathrm{E}$ between different restorative materials

\begin{tabular}{|c|c|c|c|c|}
\hline & Filtek Posterior & TetricEvoCeram & SonicFill & P Value \\
\hline Artificial saliva & $1.4150 \pm 0.23296^{\mathrm{a}, 1}$ & $1.6970 \pm 0.20000^{\mathrm{a}, 1}$ & $1.7890 \pm 0.18424^{\mathrm{a}, 1}$ & $>0.05$ \\
\hline Coca-Cola & $5.5689 \pm 0.35897^{\mathrm{b}, 1}$ & $6.4140 \pm 0.23627^{\mathrm{b}, 2}$ & $7.4010 \pm 0.37239^{\mathrm{b}, 3}$ & $<0.0001$ \\
\hline Orange juice & $4.352712 \pm 0.33338^{\mathrm{c}, 1}$ & $5.3210 \pm 0.22123^{\mathrm{c}, 2}$ & $6.4350 \pm 0.29205^{\mathrm{c}, 3}$ & $<0.0001$ \\
\hline P Value & $<0.0001$ & $<0.0001$ & $<0.0001$ & \\
\hline
\end{tabular}

Different superscript letters in columns indicate significant differences between pairs within the same group. $($ Tukey's, $P<0.0001)$ Different superscript numbers in rows indicated significant differences between values within the same subgroup. $($ Tukey's,P<0.0001) 


\section{DISCUSSION}

Color stability of dental resin composites is an important factor considered for durability of the restorations, as alteration of the restoration color can compromise its esthetic acceptance. ${ }^{35}$ Several studies have been carried out to investigate the effect of different beverages on the color stability of conventional resin composites, but little confirmed information are available about the recently marketed bulk-fill resin composites.

Although it is recommended that bulk-fill resin composites could be applied in increment thickness of up to $4 \mathrm{~mm}$, it was reported that color changes were increased with increasing the increment thickness. ${ }^{36}$ Therefore the samples in this study were prepared in one increment of $2 \pm 1$ thickness, to avoid promotion of color changes by the thick materials.

The CIE $1 * \mathrm{a}^{*} \mathrm{~b} *$ coordinate color system, chosen in the current study, is a standard method for measuring color differences based on human perception. To obtain approximately one-month constant consumption of the coloring beverages in vivo, samples should be continuously exposed to these beverages for 24 hours at $37 \pm 1^{\circ} \mathrm{C}$ in vitro. ${ }^{34}$ The null hypothesis tested that there is no influence on the color behavior of different types of bulk-fill resin composites immersed in the different drinkswas totally rejected.

It is reported that color susceptibility of bulkfill resin composites, unlike conventional resin composite, is increased; due to a verity of differences in their composition..$^{37}$ Add to that, when assessing the color stability of the resin restorative materials, a value of $\Delta \mathrm{E}$ value $\leq 3.3$ is considered clinically accepted. ${ }^{38}$ That is why storage in artificial saliva only was clinically accepted, while Coca Cola and orange juice adversely affect the color stability of the three bulk-fill resin composites with values exceeding the clinically accepted value.
As color stability is directly related to the degree of conversion of resin composite,,$^{39}$ a strict polymerization energy was adopted so that each resin composite sample received a total dose of 40 seconds, which is superior to the manufacturers' recommendations. This controlled polymerization, for all groups, reduces the influence of the lightcuring deficiency on the color stability results. ${ }^{40}$

The results of the present study showed that Filtek Posterior bulk-fill resin revealed the least material gaining discoloration in all the storage media, while SonicFill resin composite is the highest material in discoloration gaining. Several studies showed that the reason of color susceptibility of composite restorations is multifactorial, including diet, oral hygiene and materials' properties..$^{40,41}$ These material properties are resin matrix composition, resin matrix/filler interface, degree of conversion, filler content, and the degree of finishing and polishing procedures. ${ }^{42-44}$ Yet, it is thought that staining ability of resin composites is more dependent on the monomer hydrophilicity and surface roughness, rather than the filler content. ${ }^{45}$

There are two major theories to explain the fluids' absorption in resin matrix. The first one is the "free volume theory", in which it is assumed that water freely penetrates the resin matrix through nanopores present, without any chemical reaction with polymerized chains. In the second theory "interaction theory", water chemically bind to the hydrophilic groups in the polymer chains, via hydrogen bond. ${ }^{46}$ Therefore, water exists in the resin composites in two distinct forms, the unbound form freely present between the polymer chains and the nanopores created during polymerization ${ }^{47}$ and the bound form, chemically attached to polymer chains. $^{48}$

Considering the hydrophilicity of the resin monomers in the materials tested in this study, the resin matrix of Filtek Posterior bulk-fill resin composite is mainly composed of UDMA based monomers. These monomers exhibited lower 
discoloration values rather than other dimethacrilate based monomers, including Bis-GMA and TEGDMA. ${ }^{49}$ This can be attributed to the decreased water absorptionof this hydrophobic monomer, after polymerization, and lower viscosity. ${ }^{50,51}$ That is why Filtek Posterior bulk-fill resin composite has the highest values of color stability, which are significant with Coca Cola and orange juice storage media, in comparison with TetricEvoCeram bulkfill andSonicFill .

It is well established that water absorption of resin composites depends on the type of monomers in a descending pattern as follow, TEGDMA $>$ BisGMA $>$ UDMA $>$ Bis-EMA; ${ }^{29,52,53}$ leading to more pigment-susceptibilty of BisGMA and TEGDMA monomers. ${ }^{54}$ Hydroxyl groups in bis-GMA formed stronger hydrogen bonds with water molecules than urethanes group, that also could explain the high value of water absorbency.This monomer favored water sorption and increased the solubility of the polymers. Ingredients of food and drinks penetrate the resin matrix, damaging resin matrix/ filler particles interface, resulting in greater color change.$^{55}$ In this context, the hydrophilic TEGDMA monomer, with high affinity to water, revealed the highest pigmentation ratio, a case of SonicFill bulkfill resin composite..$^{41,56}$

Degree of polymerization can affect the color stability of resin composites, and intensify discoloration due to the release of monomer degradation products including methacrylic acid and formaldehyde..$^{57,58}$ Despite Bis-GMA monomer, present in TetricEvoCeram bulk-fill and Sonic-fill resins has a very strong intermolecular interaction and rigid backbone, it exhibited low degree of conversion and was prone to water uptake..$^{59,60}$ Added to that, filler incorporated in TetricEvoceram bulk-fill serves as a stress reliever, due to its low modulus of elasticity. This filler does not exist in the other two composites evaluated in this study. Therefore, this filler may also be responsible for lower color stability. ${ }^{61}$
Regardless the restorative materials, Coca Cola caused the highest degree of discoloration of the resin composite, to be followed by Orange juice with the least and insignificant color changes were noticed with storage in the artificial saliva.

The findings of this study present that storage in artificial saliva can lead to slight insignificant discoloration of the restorations. It is mandatory that water sorption didn't discolor resin composites by itself to a significant extent because water has no coloring components. water absorption and the hydrophilic/hydrophobic nature of the resin matrix, are the key factors in the staining susceptibility of resins after being immersed in water. Microcracks or interfacial gaps at the interface between the filler and matrix, are caused by plasticization and expansion the resin component due to the excessive water absorption. As a result, these microcracks allow stain penetration and discoloration of the restoration. ${ }^{62}$ In addition, discoloration might be due to the dissimilarity in the refractive index of filler and resin matrix that increases after water absorption..$^{63}$

It is reported that the low $\mathrm{pH}$ of the immersion media seems to have an influence on the absorption and solubility behavior of composite resin materials. This is because the low $\mathrm{pH}$ of a solution increases the deleterious and erosive effects on resin composite. ${ }^{64}$ It was reported that, orange juice due to its citric acid content and Coca Cola, due to its carbonic and phosphoric acid content can result in discoloration and staining of composite resin. ${ }^{65}$ The visible color change in resin composites be due to penetration of the pigments into the composite microcracks.

Coca Cola, a yellow-brown carbonated beverage, contains orthophosphoric and carbonic acids lowering its $\mathrm{PH}$ to approximately 2.4 ; while Orange juice has yellow stains and $\mathrm{pH}$ of 3.8 due to the presence of citric acid. ${ }^{66,67}$ That is why it is reported that color change was higher in Coca Cola compared to orange juice. 


\section{CONCLUSIONS}

Under the conditions of the present study it can be concluded that:

1. Bulk-fill resin composites, investigated in this study, showed less color stability than incremental resin composites.

2. Acidic drinks have deteriorating effects on color of resin composite restorations.

\section{REFERENCES}

1. Lee IB, Cho BH, Son HH, Um CM. A new method to measure the polymerization shrinkage kinetics of light cured composites. J Oral Rehabil 2005; 32:304-314.

2. Cara RR, Fleming GJ, Palin WM, Walmsley AD, Burke FJ. Cuspal deflection and microleakage in premolar teeth restored with resin-based composites with and without an intermediary flowable layer. J Dent 2007; 35 : 482-489.

3. Lutz F, Krejci I, Barbakow F. Quality and durability of marginal adaptation in bonded composite restorations. Dent Mater 1991;7:107-113.

4. Dauvillier BS, Aarnts MP, Feilzer AJ. Developments in shrinkage control of adhesive restoratives. J Esthet Dent 2000;12:291-299.

5. Feilzer AJ, Dooren LH, de Gee AJ, Davidson CL. Influence of light intensity on polymerization shrinkage and integrity of restoration-cavity interface. Eur J Oral Sci 1995; 103: 322-326.

6. Alomari QD, Reinhardt JW, Boyer DB. Effect of liners on cusp deflection and gap formation in composite restorations. Oper Dent 2001; 26:406-411.

7. McCullock AJ, Smith BG. In vitro studies of cuspal movement produced by adhesive restorative materials. Br Dent J 1986; 161:405-409.

8. Lee MR, Cho BH, Son HH, Um CH, Lee IB. Influence of cavity dimension and restoration methods on the cusp deflection of premolars in composite restoration. Dent Mater 2007; 23:288-295.

9. Lopes GC, Viera LCC, Araujo E. Direct composite resin restorations: a review of some clinical procedures to achieve predictable results in posterior teeth. J Esthet Rest Dent 2004; 16: 19-31.
10. Lopes GC, Baratieri LN, Monteiro S, Viera LCC. Effect of posterior resin composite placement technique on the resin-dentin interface formed in vivo. Quintessence Int 2004; 35: 156-160.

11. Roopa R, Anupriya B. Effect of four different placement techniques on marginal microleakage in class II restorations: An in vitro study. World J Dent 2011;2:111-6

12. ChandrasekharV, RudrapatiL, BadamiV, Tummala M. Incremental techniques in direct composite restoration. J Cons Dent 2017;20: 386-391

13. Versluis A, Douglas WH, Cross M, Sakaguchi RL. Does an incremental filling technique reduce polymerization shrinkage stresses? J Dent Res 1996; 75:871-878.

14. Kwon Y, Ferracane J, Lee IB. Effect of layering methods, composite type, and flowable liner on the polymerization shrinkage stress of light cured composites. Dent Mater 2012;28: 801-809.

15. Furness A, Tadros MY, Looney SW. Effect of bulk/incremental fill on internal gap formation of bulk-fill composites. J Dent 2014;42: 439-449.

16. Czasch P, Ilie N. In vitro comparison of mechanical properties and degree of cure of bulk fill composites. Clin Oral Investig 2013;17: 227-235.

17. Ilie $\mathrm{N}$, Hickel R. Investigations on a methacrylate-based flowable composite based on the SDR technology Dent Mater 2011;27: 348-355.

18. Leprince JG, Palin WM, Hadis MA. Progress in dimethacrylate based dental composite technology and curing efficiency. Dent Mater 2013;29: 139-156.

19. El-Damanhoury H, Platt J. Polymerization shrinkage stress kinetics and related properties of bulk-fill resin composites. Oper Dent 2014;39: 374-382.

20. Ferracane JL. Resin-based composite performance: Are there some things we cannot predict? Dent Mater 2013;29:51-58.

21. Ilie N, Bucuta S, Draenert M. Bulk-fill resin-based composites: an in vitro assessment of their mechanical performance. Oper Dent. 2013;38:618-625.

22. Ilie N, Rencz A, Hickel R. Investigations towards nano-hybrid resin-based composites. Clin Oral Investig. 2013;17:185-193.

23. Alshali RZ, Salim NA, Satterthwaite JD, Silikas N. Long-term sorption and solubility of bulk-fill and conventional resin-composites in water and artificial saliva. J Dent. 2015;43:1511-1518. 
24. Fronza BM, Rueggeberg FA, Braga RR, Mogilevych B, Soares LE, Martin AA, Ambrosano G, Giannini M. Monomer conversion, microhardness, internal marginal adaptation, and shrinkage stress of bulk-fill resin composites. Dent Mater. 2015;31:1542-1551.

25. Rosatto CM, Bicalho AA, Veríssimo C, Bragança GF, Rodrigues MP, Tantbirojn D, Versluis A, Soares CJ. Mechanical properties, shrinkage stress, cuspal strain and fracture resistance of molars restored with bulk-fill composites and incremental filling technique. J Dent. 2015;43:1519-1528.

26. Marigo L, Spagnuolo G, Malara F, Martorana GE, Cordaro M, Lupi A, Nocca G. Relation between conversion degree and cytotoxicity of a flowable bulk-fill and three conventional flowable resin-composites. Eur Rev Med Pharmacol Sci. 2015;19:4469-4480.

27. Dietschi D, Campanile G, Holz J, Meyer JM. Comparison of the color stability of ten new-generation composites: an in vitro study. Dent Mater. 1994;10:353-362.

28. Lie N, Kebler A, Duner J: Influence of various irradiation processes on the mechanical properties and polymerization kinetics of bulk-fill resin based composite. J Dent, 2013; 41:695-702

29. Bagheri R, Burrow MF, Tyas M. Influence of food-simulating solutions and surface finish on susceptibility to staining of aesthetic restorative materials. J Dent. 2005; 33:389-398.

30. Sarafianou A, Iosifidou S, Papadopoulos T, Eliades G. Color stability and degree of cure of direct composite restoratives after accelerated aging. Oper Dent. 2007; 32:406-411.

31. Barutcigil Ç, Yıldız M. Intrinsic and extrinsic discoloration of dimethacrylate and silorane based composites. J Dent. 2012;40:57-63.

32. Türkün LS, Türkün M. Effect of bleaching and repolishing procedures on coffee and tea stain removal from three anterior composite veneering materials. J Esthet Restor Dent 2004;16: 290-301.

33. Guler AU, Yilmaz F, Kulunk T, Guler E, Kurt S. Effects of different drinks on stainability of resin composite provisional restorative materials. J Prosthet Dent 2005; 94 : 118-124.

34. Kumar MS, Ajay R, Sahib SAM, Chittrarasu M, Navarasu M, Ragavendran N, Mohammed OFB. Color Stability Assessment of Two Different Composite Resins with Vari- able Immersion Time Using Various Beverages: An In vitro Study. J Pharm Bioallied Sci. 2017; 9: S161-S165.

35. Roselino LMR, Cruvinel DR, Chinelatti MA, Pires-deSouza FCP. Effect of brushing and accelerated ageing on color stability and surface roughness of composites. $\mathrm{J}$ Dent. 2013; 41:54-56.

36. Shamszadeh S, Sheikh-Al-Eslamian SM, Hasani E, Abrandabadi AN, Panahandeh N , Color Stability of the Bulk-Fill Composite Resins with Different Thickness in Response to Coffee/Water Immersion. Int J Dent. 2016; 2016: 7186140 .

37. Ertas E, Guler AU, Yucel AC, Koprulu H, Guler E. Color stability of resin composites after immersion in different drinks. Dent Mater J. 2006;25:371-6.

38. Orłowski M., Tarczydło B., Chałas R. Evaluation of marginal integrity of four bulk-fill dental composite materials: in vitro study. The Scient Wo J. 2015;2015:8.

39. Kamheya M, Gumustas B, Efes BG. Color stability of bulk-fill composites exposed to different beverages and the effect of whitening dentifrices. Oral Health Care, 2018;3:1-6.

40. Aguiar FH, Georgetto MH, Soares GP, Catelan A, Dos Santos PH, Ambrosano GM, et al. Effect of different lightcuring modes on degree of conversion, staining susceptibility and stain\&apos;s retention using different beverages in a nanofilled composite resin. J Esthet Restor Dent. 2011; 23:106-114.

41. Sabatini C. Color stability behavior of methacrylate-based resin composites polymerized with light-emitting diodes and quartz-tungsten-halogen. Oper Dent. 2015; 40:271-81.

42. Domingos PA, Garcia PP, Oliveira AL, Palma-Dibb RG. Composite resin color stability: influence of light sources and immersion media. J Appl Oral Sci. 2011;19:204-11

43. Sirin Karaarslan E, Bulbul M, Yildiz E, Secilmis A, Sari F, Usumez A. Effects of different polishing methods on color stability of resin composites after accelerated aging. Dent Mater J. 2013;32:58-67.

44. Barakah HM, Taher NM. Effect of polishing systems on stain susceptibility and surface roughness of nanocomposite resin material. J Prosthet Dent. 2014;112:625-631.

45. Bociong K, Szczesio A, Sokolowski K, Sokolowski MDJ, Krasowski M, Lukomska-Szymanska M. The Influence of Water Sorption of Dental Light-Cured Composites on Shrinkage Stress. Materials 2017, 10, 1142-1153. 
46. Gönülol N, Yilmaz F. The effects of finishing and polishing techniques on surface roughness and color stability of nanocomposites. J Dent. 2012;40:e64-e70.

47. Bellenger, V, Verdu, J, Morel E. Structure-properties relationships for densely cross-linked epoxide-aminesystems based on epoxide or amine mixtures. J. Mater. Sci. 1989, 24, 63-68.

48. Vanlandingham M.R, Eduljee R.F, Gillespie JW. Moisture diffusion in epoxy systems. J. Appl. Polym. Sci. 1999, 71, 787-798.

49. Sideridou, I.; Tserki, V.; Papanastasiou, G. Study of water sorption, solubility and modulus of elasticity of lightcured dimethacrylate-based dental resins. Biomat 2003, 24, 655-665.

50. Khokhar ZA, Razzoog ME, Yaman P. Colour stability of restorative resins. Quintessence Int 1991;22:733-737.

51. Khan Z, von Fraunhofer JA, Razavi R. The staining characteristics, transverse strength and microhardness of a visible light cured tenture base material. J Prosthet Dent 1987;57:384-386.

52. Sideridou, I.D.; Karabela, M.M.; Vouvoudi, E.C. Physical properties of current dental nanohybrid and nanofill lightcured resin composites. Dent. Mater. 2011, 27, 598-607.

53. Boaro, L.C.; Gonçalves, F.; Guimarães, T.C.; Ferracane, J.L.; Pfeifer, C.S.; Braga, R.R. Sorption, solubility, shrinkage and mechanical properties of "low-shrinkage" commercial resin composites. Dent. Mater. 2013, 29, 398-404.

54. Wei, Y.; Silikas, N.; Zhang, Z.; Watts, D.C. Diffusion and concurrent solubility of self-adhering and new resin-matrix composites during water sorption/desorption cycles. Dent. Mater. 2011, 21, 97-205.

55. Ardu, S, Braut V, Gutemberg D, Krejci I, Dietschi D, Feilzer AJ. A long-term laboratory test on staining susceptibility of esthetic composite resin materials. Quintessence Int. 2010; 41:695-702.

56. Yesilyurt C, Yoldas O, Altintas SH, Kusgoz A Effects of food-simulating liquids on the mechanical properties of a silorane-based dental composite. Dent Mater J 2009,28: 362-367.

57. Barakah HM, Taher NM Uzay Koc-Vural,1 Ismail Baltacioglu,2 and Pinar Altinci3 Color stability of bulk-fill and incremental-fill resin-based composites polished with aluminum-oxide impregnated disks. Restor Dent Endod. 2017 May; 42: 118-124

58. Silami, Aguilar FG, Roberti Garcia Lda F, Cruvinel DR, Sousa AB, de Carvalho Panzeri Pires-deSouza F. Color and opacity of composites protected with surface sealants and submitted to artificial accelerated aging. Eur J Dent 2012;6:24-33.

59. Silami FD, Mundim FM, Garcia Lda F, Sinhoreti MA, Pires-de-Souza Fde C. Color stability of experimental composites containing different photoinitiators. J Dent 2013;41:e62-e66.

60. Aguiar F H B, Georgtto M H, Soares G P, Catelan A, Dos Santos P H, Ambrosano G H B: Effect of different light curing modes on degree of conversion, staining susceptibility and stain's retention using different beverages in a nano-filled composite resin; J.Esthe restor Dent, 2011; 23:115-121

61. Gajewski, V.E.S. Monomers used in resin composites: degree of conversion, mechanical properties and water sorption/solubility. Braz. Dent. J. 2012, 23, 508-514.

62. Farhad Ameri 2 Maryam AbdoTabrizi 3 Amir Ghasemi 4 Ahmad Najafi 5 Afrooz Nakhostin 6 Hanieh Norouzi*7 Fatemeh Raoufinejad. Color Stability of Two Bulk-Fill Composite Resins. Journal of Dental School 2015; 33: 238-244

63. Bagheri R.,Tyas M.J.,Burrow M.F.Subsurface degradation of resin-based composites. Dental Materi. 2007; 23:944951.

64. Shortcill A. C., Palin W. M., Burtscher P. Refractive index mismatch and monomer reactivity influence composite curing depth. J of Dent Res. 2008;87:84-88.

65. Ortengren U, Andersson F, Elgh U, Terselius B, Karlsson $\mathrm{S}$. Influence of $\mathrm{pH}$ and storage time on the sorption and solubility behavior of three composite resin materials. $\mathrm{J}$ Dent. 2001;29:35-41.

66. Galten A, Briso AL, Sundfeld RH, Goiato MC, Santos PH. Color stability of sealed composite resin restorative materials after ultraviolet artificial aging and immersion in staining. J Prosthet Dent. 2011 April; 105:236-241.

67. Neamat A, LinlinH, Akira OK. Changes in the mechanical properties and surface texture of compomer immersed in various media. J Prosthet Dent. 2000 Oct; 84:444-520. 